\title{
Revista Brasileira de Enfermagem REBEn \\ 0 ensino do brinquedo/brinquedo terapêutico nos cursos de Graduação em Enfermagem no Estado de São Paulo
}

\author{
The teaching of play/therapeutic play in Nursing schools in São Paulo State \\ La enseñanza del juguete/juguete terapéutico en las Escuelas de Enfermería en \\ el Estado de São Paulo
}

\section{Sílvia Maira Pereira Cintra}

Professor Colaborador Assistente I da Disciplina Enfermagem Pediátrica da Universidade de Taubaté, SP. Membro do Grupo de Estudos do Brinquedo, do Núcleo de Estudos da Criança e do Adolescente da UNIFESP.

\section{Conceição Vieira da Silva}

Professor Adjunto da Disciplina Enfermagem Pediátrica do Departamento de Enfermagem da UNIFESP, São Paulo, SP. Presidente da Sociedade Brasileira de Enfermeiros Pediatras (SOBEP).

\section{Circéia Amália Ribeiro}

Professor Adjunto da Disciplina Enfermagem Pediátrica do Departamento de Enfermagem da UNIFESP, São Paulo, SP. Coordenadora do Grupo de Estudos do Brinquedo, do Núcleo de Estudos da Criança e do Adolescente da UNIFESP. Vice Presidente da Sociedade Brasileira de Enfermeiros Pediatras (SOBEP).
Submissão: 06/12/2005

Aprovação: 18/04/2006

\section{RESUMO}

Este estudo é uma pesquisa quantitativa, descritiva, com os objetivos de caracterizar o ensino do brinquedo/ brinquedo terapêutico e analisar as facilidades e dificuldades de seu desenvolvimento nos cursos de graduação em enfermagem do Estado de São Paulo. Os dados foram coletados em 40 instituições, tendo como sujeitos participantes 76 docentes. Os resultados demonstraram que a temática é abordada no conteúdo programático da disciplina Enfermagem Pediátrica na maioria das instituições, na $3 .^{a}$ série, mais efetivamente nos últimos dez anos, tanto no ensino teórico como prático. A carga horária teórica variou de uma a 20 horas, foram utilizadas aulas expositivas e participativas e na estratégia de avaliação teórica prevaleceu a prova escrita e na prática, a observação do aluno. Algumas facilidades e dificuldades citadas se referem à valorização e a infraestrutura favoráveis a este recurso.

Descritores: Educação em enfermagem; Jogos e brinquedos; Enfermagem pediátrica.

\section{ABSTRACT}

This study is a descriptive and quantitative research that aims to characterize the toy / therapeutic toy teaching and analyze the facilities and difficulties of its development in the graduation courses in nursing in Sao Paulo State. The data was collected in 40 institutions, where there were 76 participant professors. The results showed that the theme is approached in the programmatic content of Pediatric Nursing in most of these institutions, in the third, more effectively in the last ten years, both in the theoretical and practical teaching. The theoretical load time had a variation of one to 20 hours, using expositive and participative class and the written test prevailed in the theoretical evaluation strategies and in the practical, the students observation. Some difficulties and facilities mentioned refer to valorization and to infra structure favorable to these resources.

Descriptors: Educqation, nursing; Play and playthings; Pediatric nursing.

\section{RESUMEN}

Este estudio es una pesquisa cuantitativa, descriptiva, con los objetivos de caracterizar la enseñanza del juguete/juguete terapéutico y analizar las facilidades y dificultades de su desarrollo en los cursos de graduación en enfermería del Estado de São Paulo. Los datos fueron obtenidos en 40 instituciones, del cual participaron 76 catedráticos. Los resultados demostraron que la temática fue abordada en el programa de la disciplina de Enfermería Pediátrica, en la mayoria de estas instituciones, en el tercer año del curso, más efectivamente en los últimos diez anõs, tanto en la enseñanza teórica, como en la práctica. La carga horaria teórica varió de una a veinte horas, utilizando clases expositivas y participativas. Como estrategia de evalución teórica prevaleció el examen escrito y en la práctica, la observación del alumno. Algunas facilidades y dificultades citadas, se refieren a la valoración e infraestructura favorable de estos recursos.

Descriptores: Educación en enfermería; Juegos y implementos de juegos; Enfermería pediátrica.

Cintra SMP, Silva CV, Ribeiro CA. O ensino do brinquedo/brinquedo terapêutico nas Escolas de Graduação em Enfermagem no Estado de São Paulo. Rev Bras Enferm 2006 jul-ago; 59(4):497-501.

\section{INTRODUÇÃO}

\section{A criança e o brinquedo/brinquedo terapêutico}

A prestação da assistência de enfermagem à criança, independente do contexto em que esteja ocorrendo, é algo abrangente. Além da execução adequada da técnica ou do domínio dos conhecimentos relacionados a determinada patologia, exige que a criança e sua família sejam contempladas como um todo: atender suas necessidades emocionais, estabelecer vínculos com ela e a família, saber compreendê-la, conforme a fase de desenvolvimento em que se encontra e, especialmente, quando vivencia um processo de doença. 
Como recurso facilitador da intervenção de enfermagem, temos 0 brinquedo. Pela Declaração dos Direitos da Criança das Nações Unidas, a necessidade de brincar é vista como essencial à criança( ${ }^{(1)}$. O Estatuto da Criança e do Adolescente, reafirma a importância do brincar; no Artigo 16, item IV - "brincar, praticar esportes e divertir-se"(2).

Brincar é importante à criança, e a equipe profissional deve reconhecer essa necessidade, propiciar meios para sua realização e incorporá-la de forma sistemática na assistência diária. Como afirma D’Antonio, "a enfermeira é um orquestrador que facilita a brincadeira da criança"(3).

Se esta necessidade não for suprida, poderá ocasionar distúrbios comportamentais, como: alterações no sono, irritabilidade excessiva, agressividade, falta de adequação social e o não favorecimento de desenvolvimento e crescimento saudáveis da criança $a^{(4,5)}$.

A brincadeira pode ser classificada em dois tipos: a recreacional, atividade não estruturada, na qual a participação da criança é espontânea, a fim de obter prazer, promover a interação entre crianças, e terapêutica, atividade estruturada, conduzida por profissionais que conhecem sua técnica de aplicação e visa a promover o bem-estar físico e emocional da criança que vivencia uma situação incomum à sua idade $e^{(6,7)}$.

Dentre as brincadeiras terapêuticas, encontramos a ludoterapia e 0 brinquedo terapêutico, este se fundamenta na função catártica do brinquedo e aplica princípios de ludoterapia ${ }^{(8)}$. Cabe descrever a diferença entre essas duas modalidades de intervenção.

Ludoterapia: é uma técnica psiquiátrica, utilizada para tratamento de crianças com algum distúrbio psicológico, sua meta é facilitar a compreensão dos comportamentos e sentimentos pela própria criança. Deve ser conduzida por um psiquiatra, psicólogo ou enfermeiro especializado em um local preparado para esse fim ${ }^{(0-10)}$.

Brinquedo Terapêutico: é um brinquedo estruturado que possibilita à criança aliviar a ansiedade gerada por experiências atípicas para sua idade que costumam ser ameaçadoras e requerem mais do que recreação, para que sejam resolvidas ${ }^{(11)}$. Não exige local específico para sua aplicação. As sessões de brinquedo terapêutico são de 15 a 45 minutos, podem ser feitas diariamente ou apenas uma vez e seu principal objetivo é favorecer ao profissional a compreensão das necessidades da criança $a^{(9)}$.

De acordo com sua finalidade e a intenção de seu uso, o brinquedo terapêutico pode ser classificado em três tipos:

Brinquedo Terapêutico Dramático: sua finalidade é permitir à criança exteriorizar as experiências que tem dificuldade de verbalizar, a fim de aliviar tensão, expressar sentimentos, necessidades e medos(6,10,12).

Brinquedo Terapêutico Instrucional: indicado para preparar e informar a criança dos procedimentos terapêuticos a que deverá se submeter, com a finalidade de se envolver na situação e facilitar sua compreensão a respeito do procedimento a ser realizado(6).

Brinquedo Terapêutico Capacitador de Funções Fisiológicas: utilizado para capacitar a criança para o autocuidado, de acordo com 0 seu desenvolvimento, condições físicas e prepará-la para aceitar a sua nova condição de vida ${ }^{(6)}$.

Na sessão do brinquedo terapêutico, além dos materiais específicos referentes ao procedimento a ser realizado na criança, deve-se assegurarIhe, um ambiente aconchegante e seguro, pois é essencial que durante a sessão de brinquedo terapêutico, ela perceba a presença de um adulto aceitador que a encoraje a expressar seus sentimentos ${ }^{(13)}$.

0 ensino do Brinquedo/Brinquedo Terapêutico na enfermagem

$O$ ensino de graduação em enfermagem considera os pressupostos da Lei de Diretrizes e Bases da Educação Nacional (LDBN), Lei n. ${ }^{\circ 9.394 / ~}$ 96 ${ }^{(14)}$; assim como as Diretrizes Curriculares Nacionais, para que o futuro profissional tenha uma formação generalista e, enfrente o mercado de trabalho.

Os projetos pedagógicos, apoiados nas Diretrizes Curriculares Nacionais dos Cursos de Graduação em Enfermagem ${ }^{(15)}$ devem se fundamentar em princípios educacionais que garantam a flexibilidade dos currículos, a consideração dos estudantes, como sujeitos do processo ensino-aprendizagem e dos professores, como facilitadores do processo.

Assim, devem contemplar também a articulação teoria e prática, a pesquisa integrada ao ensino e à extensão, o uso de metodologias ativas no processo ensino e ou aprendizagem, a diversificação dos cenários de aprendizagem, a elaboração de currículos fundamentados no humanismo, a avaliação formativa, a educação orientada aos problemas relevantes da sociedade e a terminalidade dos cursos $^{(16)}$.

Entre as novas tendências filosóficas do cuidado à criança, destacase a prestação da assistência atraumática que pressupõe intervenções voltadas a eliminar ou minimizar os desconfortos físicos e psicológicos experimentados pelas crianças e seus familiares, seja na realização de um procedimento ou quando vivenciam a internação hospitalar ${ }^{(17)}$. Como recurso para esta assistência de enfermagem efetiva e atraumática destaca-se o emprego do brinquedo/brinquedo terapêutico.

No Brasil, o ensino do brinquedo, como recurso de intervenção na assistência de enfermagem à criança, iniciou-se no final da década de 1960, com a Profa. Dra. Esther Moraes, na época, docente na Disciplina Enfermagem Pediátrica da Escola de Enfermagem da Universidade de São Paulo (EEUSP) ${ }^{(8)}$.

Em entrevista com a Profa. Dra. Esther Moraes, para melhor conhecer a situação, ela afirmou ser o brinquedo dramático uma forma de interação entre pessoas e começou a utilizá-lo na assistência à criança, intuitivamente, durante a observação de situações traumatizantes à criança $a^{(18)}$.

A partir de então, constatou menor sofrimento e maior cooperação quanto ao tratamento, quando a criança tinha a oportunidade de repetir os procedimentos em bonecas ou conversar com as mesmas. Verificou que o brincar amenizava o sofrimento ocasionado pela separação de seus pais na hospitalização. Percebeu que, por meio dessa assistência, havia maior aproximação entre o adulto e o pequeno paciente, tornando, assim, o cuidado individualizado.

Quanto à facilidade ou dificuldade no emprego do brinquedo pelos alunos, a Prof. ${ }^{a}$ Dra. Esther refere que dependia da prontidão dos estudantes; isto é, sua capacidade de envolvimento e entrega a algo novo e desconhecido. Relata que aqueles que estavam "amarrados" em si mesmos, não conseguiam se beneficiar das propriedades que o emprego do brinquedo poderia proporcionar a seu processo de aprendizagem.

$\mathrm{Na}$ entrevista, a professora fez sugestões para trabalhar com 0 brinquedo no ensino, que consideramos princípios norteadores para nossas ações, como docentes de Enfermagem Pediátrica: tratar 0 estudante como pessoa; dar fundamentação sobre a estrutura da personalidade; expor a conceituação filosófica de Carl Rogers a respeito da natureza humana; apresentar aos alunos bibliografias, por vezes, com imagem e som, de experiências com emprego do brinquedo dramático: preparar os estudantes para o relacionamento terapêutico e condutas da comunicação dirigida e não dirigida; considerar as medidas de controle de infecção, sem prejudicar a manipulação dos brinquedos pelas crianças; criar ambiente privativo para o pequeno paciente vivenciar seu brinquedo dramático.

Hoje, a abordagem desta temática no ensino de graduação em enfermagem é recomendada pelos órgãos profissionais: o Conselho Federal de Enfermagem (COFEN), pela Resolução N. ${ }^{\circ}$ 295/2004 e o Conselho Regional de Enfermagem -SP (COREN-SP), pela PRCI N. ${ }^{\circ}$ 5.1669 , a fim de assegurar ao profissional enfermeiro, em sua prática, 0 emprego da técnica do brinquedo/brinquedo terapêutico na assistência à criança e sua familia ${ }^{(19,20)}$.

\section{OBJETIVOS}

Caracterizar o ensino do brinquedo/brinquedo terapêutico e analisar as facilidades e dificuldades de seu desenvolvimento nos cursos de 
Graduação em Enfermagem do Estado de São Paulo.

\section{MÉTODO}

O estudo é uma pesquisa quantitativa descritiva. A população compôsse pelos docentes da disciplina Enfermagem Pediátrica que ministram aulas nos cursos de Graduação em Enfermagem no Estado de São Paulo.

Como critério de seleção definiu-se que participariam da amostra os cursos de Graduação em Enfermagem com sua data de início de funcionamento até 0 ano de 2000, já tendo formado sua primeira turma em 2004.

Assim, totalizaram-se 49 instituições e 141 docentes, dos quais, 40 instituições e 76 docentes responderam aos questionários. Este se compôs de questões estruturadas, semi-estruturadas e abertas, contemplando as variáveis do estudo: perfil docente, caracterização da instituição e da disciplina Enfermagem Pediátrica em relação ao brinquedo/brinquedo terapêutico, e sua experiência pessoal do docente no ensino da temática.

A coleta de dados verificou-se de 1 de junho a 21 de setembro de 2004. Antes de ser iniciada, o projeto do estudo obteve a aprovação do Comitê de Ética em Pesquisa da Universidade Federal de São Paulo, sob o CEP N. ${ }^{\circ}$ 1497/03.

A análise dos dados quantitativos será apresenta em valores porcentuais e aos dados qualitativos, as premissas da análise de conteúdo de Bardin ${ }^{(21)}$.

\section{RESULTADOS E DISCUSSÃO}

\section{Caracterização da disciplina Enfermagem Pediátrica}

A disciplina Enfermagem Pediátrica é ministrada na $3^{\mathrm{a}}$ série do curso, em $75,0 \%$ das instituições, e os docentes que a lecionam, têm experiência mínima de um e máxima de 32 anos; mas a maioria, $(53,3 \%)$ leciona entre um e dez anos a disciplina.

Ao analisar a relação entre tempo que o docente leciona na disciplina Enfermagem Pediátrica e o tempo que o brinquedo/brinquedo terapêutico é abordado na instituição onde atua, constatou-se que os docentes que lecionam na disciplina Enfermagem Pediátrica no período de um a 15 anos, abordam o tema brinquedo/brinquedo terapêutico no ensino entre oito e dez anos. Ao passo que os docentes que lecionam na disciplina, há mais de 15 anos, abordam a temática no ensino, há menos tempo, sendo esta média menor que cinco anos.

Isto pode estar relacionado ao fato dos docentes mais novos já terem tido a abordagem dessa temática em sua formação, tanto na graduação como na pós-graduação, visto que o incremento do ensino e da pesquisa a respeito da temática em nosso País deu-se a partir da década de 1980.

A abordagem do tema brinquedo/brinquedo terapêutico no conteúdo programático da disciplina Enfermagem Pediátrica, em 38 instituições, ocorre tanto no ensino teórico como no prático. A maioria dos docentes $(69,1 \%)$ aborda a temática e a ensina, tanto na teoria como na prática, $21,8 \%$ abordam na prática e $9,1 \%$ na teoria. O fato de só $9,1 \%$ abordarem na teoria, leva-nos ao seguinte questionamento: será que os alunos desses docentes estão vivenciando o ensino dessa prática com outro professor? Como será a integração entre os docentes da teoria e prática, para que o ensino do brinquedo/brinquedo terapêutico seja efetivo? Será que só a abordagem na teoria é capaz de promover que o aluno sedimente e valorize a utilização desse recurso na prática, de forma a utilizá-lo na vida profissional futura?

Os docentes abordam a temática no conteúdo programático da disciplina pelo fato de se sentirem motivados a utilizar esse recurso, pelo reconhecimento de sua importância, como instrumento da assistência à criança; meio que propicia a expressão dos sentimentos, a comunicação, a liberação de estresse, a interação criança-família-profissional e minimiza o impacto da hospitalização, sendo fundamental no crescimento e desenvolvimento infantis, conforme pode ser verificado nos relatos de alguns docentes:

Consideramos importante o uso do brinquedo, pois, sabe-se que através dele, a criança pode enfrentar o processo de hospitalização de uma forma mais tranqüila e menos traumática.(27)

Acredito nesta prática na mediação entre o profissional, o cliente e a familia, durante principalmente as técnicas evasivas e dolorosas.(41)

Esta visão dos docentes corrobora com os achados da literatura que consideram a importância do uso do brinquedo terapêutico pelo enfermeiro para identificar distintos aspectos e fatores que devem influenciar 0 desenvolvimento da criança, para assim, prestar uma assistência mais humanizada ${ }^{(8,22)}$.

\section{Caracterização do ensino teórico e prático do brinquedol} brinquedo terapêutico

Em relação aos objetivos, para o desenvolvimento do conteúdo programático da disciplina Enfermagem Pediátrica relacionados à temática, estes, foram agrupados conforme o sujeito da ação pedagógica: criança; criança e família; criança, família e equipe; relação interpessoal; estudante de enfermagem e brinquedo/brinquedo terapêutico.

A carga horária teórica destinada ao ensino da temática, varia de uma a 20 horas.

Este achado levou-nos a refletir sobre a adequação dessa carga horária, em especial, quando existe apenas uma hora/aula para discutir 0 referencial teórico e a metodologia de sua utilização, o que conforme nossa experiência é pequena para se motivar 0 aluno quanto à sua importância na assistência à criança.

Em relação a como o docente fez para introduzir a temática no conteúdo programático da referida disciplina, os docentes relatam que foram impulsionados pela filosofia norteadora da assistência, ou seja, não conceber lidar com a criança sem considerar as brincadeiras; pela importância da temática para a formação do futuro enfermeiro; por considerar o tema como um instrumento facilitador para a abordagem das temáticas: desenvolvimento infantil, preparo da criança para procedimentos intrusivos e exame físico, conforme mostram os relatos de alguns docentes:

Sempre fez parte de minha concepção enquanto docente de pediatria e não consigo ver crianças longe de brincadeiras. (39)

Comecei a usar o brinquedo na consulta de enfermagem para avaliar o desenvolvimento da criança, depois usamos a música para distrair a criança durante procedimentos desagradáveis, o exame físico. Hoje, usamos "bolinha de sabão" é mágico. Experimente! (1)

Os comentários dos docentes em relação à abordagem da temática no conteúdo da disciplina apresentam vários atributos que reafirmam a importância do emprego do brinquedo/brinquedo terapêutico na assistência à criança e com sugestões de como realizá-lo, confirmando que o uso do brinquedo exerce um papel importante na assistência à criança, como aparece ressaltado nos vários trabalhos anteriormente citados.

Quanto ao número de alunos por turma em aula teórica, este varia de oito a 100. Consideramos que número muito grande de alunos por turma pode dificultar o emprego de técnicas de ensino-aprendizagem mais lúdicas e a discussão da temática, assim como tratar o aluno de forma mais individualizada, conforme sugere a Prof. ${ }^{a}$ Dra. Esther em sua entrevista ${ }^{(18)}$.

A metodologia utilizada para abordar o conteúdo relacionado ao brinquedo/brinquedo terapêutico na teoria, em 49,9\% das instituições foi a aula expositiva e participativa. Outras metodologias também foram citadas como o estudo dirigido (23,7\%), aula expositiva e seminário $(23,7 \%)$ 
e, em menor proporção, a dramatização $(2,7 \%)$. Acreditamos que a associação de estratégias que 0 docente utiliza para desenvolver 0 conteúdo programático relacionado ao brinquedo/brinquedo terapêutico possa favorecer o processo de ensino-aprendizagem. Isto é confirmado em um estudo recente sobre o emprego do brinquedo na assistência à criança, no qual os alunos de graduação apresentam sugestões para melhorar o processo ensino-aprendizagem na graduação, como "a utilização de dinâmicas para sensibilizar 0 acadêmico, envolvimento da equipe de enfermagem e maior articulação entre teoria e prática, pelo acadêmico e professor"(23).

Em relação às formas de avaliação do aluno no ensino teórico da temática, em $47 \%$ das instituições pesquisadas, o instrumento usado nesta avaliação é a prova escrita, seguida de estudo de caso, seminário e confecção de brinquedo associado a seminário.

A bibliografia básica utilizada na disciplina Enfermagem Pediátrica para desenvolver o ensino da temática em estudo, foi variada, compreendendo: artigos, livros, capítulos de livros, CD-ROM, dissertações e teses que enfocam, tanto 0 aspecto do ensino como da assistência à criança, com a utilização do brinquedo/brinquedo terapêutico. 0 achado demonstra que os docentes têm buscado não só se inovar, como também indicar referências atualizadas aos alunos.

Quanto à carga horária destinada ao ensino prático da utilização do brinquedo/brinquedo terapêutico na assistência à criança, $63,8 \%$ das instituições, referiram não ter uma carga horária prática específica. Este achado nos levou a questionar se todos os alunos estão realmente vivenciando esse recurso na prática. No caso de vivenciarem essa prática, poderá não estar havendo um planejamento pedagógico da mesma, no sentido de garantir que eles vivenciem sua aplicação no contexto assistencial.

Para o desenvolvimento do conteúdo programático relacionado ao brinquedo/brinquedo terapêutico na prática, em $71,0 \%$ das instituições, os alunos realizam a atividade prática recreativa com a criança que compreende o emprego do brinquedo recreacional na assistência. 0 brinquedo terapêutico propriamente dito é praticado em apenas 14,5\% das instituições.

Este dado nos mostra que a aplicação do brinquedo terapêutico não é realizada por todos os alunos durante a atividade prática de ensino na graduação.

0 campo de prática onde 0 aluno tem oportunidade de utilizar 0 brinquedo/brinquedo terapêutico na assistência à criança, em 50,0\% instituições é desenvolvido, tanto na área hospitalar como na área não hospitalar, em $30,5 \%$ só na área hospitalar e $19,5 \%$ na área não hospitalar.

Quanto às situações em que o aluno é orientado a utilizar o brinquedo/ brinquedo terapêutico, foram referidas: o preparo da criança para procedimentos; a necessidade de estabelecer comunicação, interação entre a criança e família; no diagnóstico, prescrição e consulta de enfermagem e realização de atividades de educação em saúde, conforme os relatos de alguns docentes:

Para realizar orientações sobre cuidados com a saúde para crianças; antes e depois da realização dos procedimentos técnicos de enfermagem, para iniciar o exame físico, quando a criança apresentase chorosa, e ansiosa. (3)

Sempre em todas prescrições de enfermagem é enfocado este item. Os alunos próprios buscam brinquedos, na maioria das vezes, se busca a estimulação.(27)

Os achados demonstram que o emprego do brinquedo/brinquedo terapêutico pelos alunos tem sido estimulado como instrumento que favorece a prestação de uma assistência integral e humanizada. Esta técnica pode ser usada em várias situações na assistência à criança; muitas vezes, cabe ao docente orientar o aluno para o momento oportuno de seu uso, de forma que possa vivenciá-la, sensibilizar-se e incorporar o brinquedo em sua assistência.

Para a avaliação do brinquedo/brinquedo terapêutico no ensino prático, $52,5 \%$ dos docentes relataram que empregam a observação do aluno no desempenho de suas atividades diárias, só $16,0 \%$ avaliam o aluno, quanto ao emprego da técnica do brinquedo terapêutico no contexto da assistência à criança.

Quanto à percepção do docente em relação à receptividade dos alunos ao abordarem o tema brinquedo/brinquedo terapêutico na prática, verificase que as informações denotam receptividade e resistência dos alunos para seu emprego, conforme os relatos de alguns docentes:

Inicialmente, não muito boa, há muita resistência, mas a hora que percebem o resultado, que melhora a interação, eles acabam utilizando mesmo sem o professor incentivá-los. (3)

Boa, ajuda também na criatividade e aproximação da criança. Favorece o relacionamento do aluno quanto a estabelecer vínculo. (32)

Desse modo, é possível observar que a receptividade dos alunos em relação ao emprego do brinquedo/brinquedo terapêutico é individual. Em vista da situação, é preciso que os docentes lancem mão de recursos que sensibilizem os alunos a empregar esta abordagem no ensino prático, pois só após conseguir aplicar a teoria na prática do cuidado, o aluno poderá reconhecer sua real importância no sentido de utilizá-lo no exercício profissional futuro.

No que se refere às facilidades dos docentes para implementação do brinquedo/brinquedo terapêutico no ensino, nos relatos encontram-se respostas que indicam a valorização desse recurso, como facilitador da assistência à criança; infra-estrutura favorável a seu emprego e existência de literatura que respalde a importância da estratégia à assistência:

A experiência do cotidiano do ensino fortalece e consolidou a importância da necessidade do BT no cuidar da criança doente ou sadia.(12)

A abordagem e finalidades são discutidas e respaldadas em literatura especializada, facilitando a análise. (46)

Os achados revelam a valorização de um importante instrumento para qualidade da assistência a ser prestada. Para tanto, esta assistência deve estar fundamentada no conhecimento científico, assim como as demais instituições de saúde tenham uma filosofia de assistência centrada não só na patologia, mas, sim, na criança e sua família.

As dificuldades na implementação do ensino prático do brinquedo/ brinquedo terapêutico, nos relatos dos docentes são mencionadas situações referentes à aplicação propriamente dita, como: falta de infra-estrutura e recursos; não valorização e despreparo dos docentes em relação à aplicação do brinquedo terapêutico e não aceitação desse recurso pela equipe profissional e dificuldade na implantação sistemática dessa intervenção, como: crença que o brinquedo é competência só do psicólogo; falta de tempo para sua aplicação e o fato do aluno não compreender a importância do brinquedo, conforme os relatos de alguns docentes:

Não utiliza como uma atividade rotineira, a enfermeira aprende na graduação, especialização e mestrado, e nunca presenciei esta atividade na prática, ou seja, é apenas teórico. (45).

Na prática, os enfermeiros resistem a utilização da técnica, por falta de tempo, sobrecarga de atividade e indisponibilidade no setor. $E$ os conflitos gerados com os profissionais da saúde mental (psicólogos) 
que não aceitam a aplicação da técnica pelas enfermeiras.(47)

Em relação à não valorização do brinquedo/brinquedo terapêutico, despreparo dos docentes e não ser competência do profissional enfermeiro a realização desta técnica torna-se necessária a capacitação desses profissionais para a demanda atual em razão da aprovação da Resolução COFEN N. ${ }^{\circ} 295 / 2004$ que considera a intervenção com o brinquedo na prática assistencial e assegura ao profissional enfermeiro o emprego da técnica na assistência à criança e família(19).

Quanto à questão da falta de infra-estrutura e de recursos nos hospitais, as instituições precisam se reestruturar para atender à Lei N. ${ }^{0} 11.104 / 05$, que preconiza a obrigatoriedade de instalação de brinquedoteca nas unidades de saúde que ofereçam atendimento pediátrico em regime de internação ${ }^{(24)}$.

\section{CONCLUSÃO}

$\mathrm{Na}$ maioria das instituições estudadas, o brinquedo/brinquedo terapêutico é abordado, tanto no ensino teórico como no prático de modo efetivo nos últimos dez anos. Os alunos têm tido a oportunidade de utilizar o brinquedo/brinquedo terapêutico na assistência à criança, tanto na área hospitalar como na área não hospitalar; porém, o brinquedo terapêutico propriamente dito é praticado em apenas $14,5 \%$ das instituições. A receptividade dos alunos pela temática é individual: pois, alguns se envolvem facilmente, outros precisam vivenciar para acreditar em sua eficácia e também existem os que não demonstram interesse pela técnica. Suas facilidades de aplicação na assistência relacionam-se à valorização desse recurso e suas dificuldades são relacionadas à aplicação e implantação do brinquedo/brinquedo terapêutico na assistência à criança.

Para tanto, o docente precisa estar ciente das dificuldades de implementação do instrumento na prática e atuar como facilitador do processo de articulação entre teoria e prática, com conhecimento e habilidades pedagógicas necessárias para motivar o aluno de maneira efetiva. Os resultados deste estudo poderão contribuir para o repensar do ensino do brinquedo/brinquedo terapêutico nos cursos de graduação em enfermagem.

\section{REFERÊNCIAS}

1. United Nations. Resolution n. 1386, 20 november 1959. Declaration of the rights of the child. Official Records of the General Assembly. New York (NY): United Nations; 1959.

2. Brasil. Câmara dos deputados. Estatuto da criança e do adolescente: Lei $n^{0} 8.069$, de 13 de julho de 1990, Lei n 8.242, de 12 de outubro de 1991, e convenção sobre os direitos da criança. $4^{\text {a }}$ ed. Brasília (DF): Câmara dos Deputados; 2003.

3. D'Antonio IJ. Therapeutic use of play in hospitals. Nurs Clin North Am 1984; 19(2): 351-9.

4. Machado DVM. O brinquedo e suas funções. An Nestlé 1977; (100): 54-8.

5. LeVieux-Anglin L, Sawyer EH. Incorporating play interventions into nursing care. Pediatr Nurs 1993; 19(5): 459-63.

6. Vessey JA, Mahon MM. Therapeutic play and the hospitalized child. J Pediatr Nurs 1990; 5(5): 328-33.

7. Ziegler DB, Prior MM. Preparation for surgery and adjustment to hospitalization. Nurs Clin North Am 1994; 29(4): 655-69.

8. Ribeiro CA, Maia EBS, Sabatés, AL, Borba RIH, Rezende MA. 0 brinquedo e a assistência de enfermagem à criança. Enferm Atual 2002; 2(24): 6-17.

9. Green CS. Compreendendo as necessidades das crianças através do brinquedo terapêutico. Nursing 1974; 4(10): 31-2.

10. Walker $\mathrm{C}$. Use of art and play therapy in pediatric oncology. J Pediatr Oncol Nurs 1989; 6(4): 121-6.

11. Steele SM. Concept of communication. In: Steele SM. Child health and the family: nursing concepts and management . New York (NY): Masson; 1981. p. 710-38.

12. Jessee PO. Nurses, children, and play. Issues Compr Pediatr Nurs 1992; 15(4): 261-9.

13. Barton $\mathrm{PH}$. Nursing assessment and intervention through play. In: Bergersen BS, Anderson EH, Duffey JLM, Rose MH, editors. Current concepts in clinical nursing. Saint Louis (MI): Mosby; 1969. p.203-7.

14. Brasil. Ministério da Educação. Lei n. 9.394 de 20 de dezembro de 1996. Estabelece as diretrizes e bases da educação nacional [texto na Internet]. Diário Oficial da República Federativa do Brasil, Brasília (DF); Ministério da Saúde; 2005. [citado 2005 Jul 08]. Disponível em: URL: https://www.planalto.gov.br/ccivil 03/Leis/L9394.htm
15. Brasil. Ministério da Educação. Conselho Nacional de Educação. Resolução CNE/CES n. 3, de 7 de novembro de 2001. Institui diretrizes curriculares nacionais do curso de graduação em enfermagem. Diário Oficial da República Federativa do Brasil 2001; 11(9): seção 1:37.

16. Fernandes JD, Ferreira SL, La Torre MPS, Santa Rosa DO, Costa HOG. Estratégias para a implantação de uma nova proposta pedagógica na escola de enfermagem da Universidade Federal da Bahia. Rev Bras Enferm 2003; 56(4): 392-5.

17. Wong DL. Whaley \& Wong. Enfermagem pediátrica: elementos essenciais à intervenção efetiva. $5 a$ ed. Rio de Janeiro (RJ): Guanabara Koogan; 1999.

18. Moraes E. Entrevista concedida a Silvia Maira Pereira Cintra por Esther de Moraes, professora (aposentada) da disciplina Enfermagem Pediátrica da Escola de Enfermagem da USP. São Paulo; 11 Fev 2005.

19. Conselho Federal de Enfermagem. Resolução n. 295/2004. Dispõe sobre a utilização da técnica do brinquedo/brinquedo terapêutico pelo enfermeiro na assistência prestada à criança hospitalizada [texto na Internet]. Rio de Janeiro (RJ): COFEN; 2004. [citado 2005 jun 22]. Disponível em: URL: http://www.portalcofen.com.br/\%5Fnovoportal/ section_int.asp?InfolD=5575\&EditionSectionID=15\&SectionParentID=

20. Conselho Regional de Enfermagem. Processo PRCI n. 51669 de 24 de junho de 2004. Parecer fundamentado sobre utilização do brinquedo terapêutico pelo enfermeiro. São Paulo (SP): COREN; 2004.

21. Bardin L. Análise de conteúdo. Lisboa: Edições 70; 1977.

22. Silva LR. A utilização do brinquedo terapêutico na prescrição da assistência de Enfermagem Pediátrica. Texto Contexto Enferm; 1998; 7(3): 96-105.

23. Silva LJ, Leite JL. Quando o brincar é cuidar: acadêmicos de enfermagem e o cuidado a crianças hospitalizadas com HIVIAIDS. Rev Soc Bras Enferm Pediatr 2004; 4(3): 69-78.

24. Brasil. Ministério da Educação. Lei n. 11.104 de 21 de março de 2005. Dispõe sobre a obrigatoriedade de instalação de brinquedotecas nas unidades de saúde que ofereçam atendimento pediátrico em regime de internação. Diário Oficial da República Federativa do Brasil; 2005 mar 22; Seção 1:1. 